Max-Planck-Institut für demografische Forschung

Max Planck Institute for Demographic Research

Konrad-Zuse-Strasse 1 - D-18057 Rostock - GERMANY

Tel +49 (0) 3812081 - 0; Fax +49 (0) 3812081 - 202;

http://www.demogr.mpg.de

MPIDR WORKING PAPER WP 2012-009

FEBRUARY 2012

\title{
Rainfall shocks, parental behavior and breastfeeding: Evidence from rural Vietnam
}

\author{
Thuan Q. Thai (thai@demogr.mpg.de) \\ Mikko Myrskylä (myrskyla@demogr.mpg.de)
}

(C) Copyright is held by the authors.

Working papers of the Max Planck Institute for Demographic Research receive only limited review. Views or opinions expressed in working papers are attributable to the authors and do not necessarily reflect those of the Institute. 
Correspondence:

Thuan Q. Thai

Address:

Konrad-Zuse-Strasse 1, 18057 Rostock, Germany

Email: thai@demogr.mpg.de

Telephone: + 49 (0) 381 2081-236

\section{Rainfall shocks, parental behavior and breastfeeding: Evidence from rural Vietnam}

Short title: Rainfall, parental behavior and breastfeeding

Thuan Q. Thai

Max Planck Institute for Demographic Research

Mikko Myrskylä

Max Planck Institute for Demographic Research

December 2011

Acknowledgements. We wish to thank Evangelos M. Falaris and the participants at the Population Association of America annual meeting in Washington D.C. 2011 for their helpful comments, and the MEASURE DHS, ICF Macro and the Center for Climatic Research, Department of Geography, University of Delaware for making the data available. 


\begin{abstract}
In developing countries, rainfall shocks around the time of birth have been shown decrease later health. The mechanism is unknown, but could run through income shocks, disease exposure, or increasing opportunity cost of parental time which influences parenting behavior. We use the Vietnam Demographic Health Surveys to study how rainfall shocks around the birth year influence a key dimension of parental behavior, breastfeeding. Consistent with the opportunity cost of time theory, rainfall reduces breastfeeding: $25 \%$ excess rainfall in the birth year decreases the proportion that is breastfed more than a year by 11 percentage points. The effect is particularly strong among farming families, for whom rainfall increases the opportunity cost of time through labor demand. These results are the first to shed light on the mechanism linking rainfall shocks and child health. Policy aiming to improve child health through breastfeeding should focus on the impact of labor demand on breastfeeding.
\end{abstract}

Key words: breastfeeding, opportunity cost of time, rainfall shock, parental behavior, Vietnam 


\section{$1 \quad$ Introduction}

Early life conditions play an important role in determining the long term health and socioeconomic outcomes. For example, epidemiological studies have documented a strong link between early life environment and later life mortality. Using historical mortality series from Sweden, Finch and Crimmins (2004, pp. 1737-38) show that reductions in cohorts' infant mortality is consistently associated with reductions in cohorts' old-age mortality. According to Finch and Crimmins, this "cohort morbidity phenotype" is formulated through a mechanism of chronic inflammation resulting from adverse early life conditions which in turn increases the risk for common oldage diseases such as cardiovascular disease or cancer. Further evidence supporting the causal link between early life disease exposure and later life health is provided by studies that exploit shocks in the disease environment (Bengtsson et al. 2000; Almond 2006; Bozzoli et al. 2009). Together, these studies suggest that reduction in infectious diseases during infancy have contributed to the historical decline in adult and old-age mortality.

In contemporary developing countries, where rural poverty is prevalent, rainfall shocks - defined as excess rain compared to the long-term average - are recognized as a one important factor determining later life health outcomes. Hoddinott and Kinsey (2001, pp. 422-23) examine the health impact of a severe negative rainfall shock (drought) on child outcomes in Zimbabwe and find that those who are exposed to a severe drought during the second year of life suffer a considerable growth faltering. Maccini and Yang (2009, pp. 1015-18), on the other hand, find a significant positive effect of a birth year rainfall shock on adult health and wealth among 
Indonesian women. Both studies argue that one important mechanism through which rainfall shock may affect health is via a negative income shock faced by rural families. For example, dry weather conditions could result in the loss of harvest, which in turn decreases household income. In another study using Indian data, Bhalotra (2010, pp. 13) includes as determinants of child mortality both rainfall shocks and state level per capita real income in the birth year. Bhalotra finds that an increase in rainfall (a positive rainfall shock) in the year of birth decreases child mortality net of changes in income. Bhalotra speculates that this direct effect of rainfall shock on child mortality could be mediated by an epidemiological mechanism with no further elaboration of this mechanism. In contrast to Bhalotra's findings, Skoufias and Vinha (2011), who analyze height among Mexican children aged one to four years, find that a positive rainfall shock is associated with negative health outcomes.

Together, these studies on rainfall and child health in developing countries suggest that rainfall during the early stages of development is an important determinant of child health. The direction of the effect, however, varies from one study to another. In addition, while the studies speculate on the mechanisms that might link rainfall to child health, none of the studies directly test any of these mechanisms. For example, Maccini and Yang (2009) focus on the health outcomes observed at ages beyond 25 years old, and thus attribute the effects to a mechanism of critical period programming, a hypothesis formulated in Barker (2001, pp. 2-3). Bhalotra (2010, pp. 15-17) on the other hand focuses on analyzing the mechanism of effect of income but not that of rainfall shock. Skoufias and Vinha (2011) estimate a total effect of rainfall shock on child health and speculate that the effect could represent the two channels of 
changes in household income and thus consumption and changes in disease prevalence. Looking more broadly, these studies hypothesized two distinct mechanisms that might link rainfall to child health: disease and income. Generally, positive rainfall shock could help improve agricultural production, income and consequently, child health. On the other hand, a rainfall shock regardless of its direction could result in changes in epidemiological environment (vector-borne or water-borne diseases) that in turn increases the disease prevalence. However, these mechanisms have not been empirically tested, and it is also possible that there are additional channels other than just income or disease.

Thus, even though it has been well established that rainfall shocks in the context of developing countries may have an important effect on child health, the mechanisms behind the effect are largely unclear. The desirable policy intervention, however, requires establishing a good understanding about the mechanisms in which shock in rainfall might exert its influence on health. Such mechanisms as income shocks or disease exposure are plausible and have received much attention in the literature. Another plausible mechanism, related to the changes in the opportunity cost of parental time, has not been explored adequately. This mechanism postulates that rainfall shocks change in the short term the economic incentives the parents face - for example, by increasing or decreasing labor demand -, therefore influencing parenting behavior and potentially child health outcomes. While evidence supporting this mechanism is available in the literature for developed countries (Dehejia and LlerasMuney 2004), there are no studies in the developing country literature which would have directly measured the changing opportunity cost of parental time, or would have directly observed parental behavior during rainfall shocks. 
In this paper we address the mechanism through which rainfall during early stages of development could affect child health by investigating the link between early life rainfall shocks and parenting behavior. In particular, we study the opportunity cost of time mechanism as a potential link between rainfall and child health. As a measure for parenting behavior we use breastfeeding, which is both an important determinant of child health, and a time-consuming activity. These two characteristics of our measure for parental behavior are crucial for the attempt to shed light on the rainfall-child health mechanism: First, breastfeeding has been recognized as an important determinant of child health and child development (Fall et al. 2011, pp. 48 and the citations therein). Thus the rainfall shock-breastfeeding link, if exists, will provide us with further insight into the role of early life conditions towards the later life outcomes. Second, breastfeeding represents a type of maternal care activity that is time consuming and likely influenced by the rainfall through the change in maternal labor demand, if the opportunity cost of time hypothesis is holds.

Using data from Vietnam, we find evidence that supports the mechanism of parental opportunity cost of time. A positive rainfall shock in the year of birth decreases the duration and prevalence of breastfeeding. We find that the effect of rainfall on breastfeeding is particularly strong among children of farming mothers, among whom we expect the rainfall to strongly increase mother's labor demand. Predicted effects show that a positive rainfall shock in the year of birth with a magnitude of 25 per cent over the long term average rainfall reduces the proportion of breastfeeding more than 12 months by 10.5 percentage points, and the proportion of breastfeeding more than 18 months by 9.2 percentage points. Our results indicate that early life rainfall shock 
could affect long term child health through its short term effect on breastfeeding, mediated by mechanism other than income or disease pathways. Further, maternal work in the rural context could also be an important determinant to breastfeeding. These findings have important policy implications for the implementation of child health and breastfeeding promotion programs in developing countries. In particular, our results suggest that policies should target maternal work, which may negatively affect child health through the reduction in breastfeeding.

The paper is organized as follows. Section 2 briefly discusses the opportunity costs of time model for breastfeeding. In Section 3, we describe the empirical approach and data. Estimation results are reported in Section 4, and Section 5 concludes.

\section{The opportunity cost of time model for breastfeeding}

The opportunity cost of time model for breastfeeding views breastfeeding as an investment by mothers in the health of their child (Chatterji and Frick 2003, pp. 8-10). The initiation and the duration of breastfeeding are decisions determined by the mother's consideration of the costs and benefits - monetary and non-monetary involved with breastfeeding. The main benefit of breastfeeding is seen in terms of the improvements in child health as well as the saving from not purchasing the formula. The cost of breastfeeding is related to the mother's value of alternative use of time, primarily in the income generating work. The World Health Organization (2003, pp. 7-8) recognizes the importance of breastfeeding by its recommendation that infants 
should be exclusively breastfed throughout the first six months in life ${ }^{1}$. Moreover, research has shown additional health benefits to children who are breastfed beyond this period. For example, these health benefits include, among others, improved cognitive development (Kramer et al. 2008), increased lower body explosive strength during adolescence (Artero et al. 2010) and reduced risk of obesity (Kramer 2010). WHO (2003, pp. 7-8) also recommends that while 6-months old infants are introduced to complementary food, mothers should continue breastfeeding their children up to two years of age or beyond to reap the full benefits of breastfeeding.

However, breastfeeding often falls short of the desirable duration. According to a review by Dennis (2002, pp. 14), most mothers stop exclusive breastfeeding much earlier than recommended by the health agencies. Several empirical studies attribute this underachievement to one major factor, which is the mother's return to work after giving birth (Roe et al. 1999; Baker and Milligan 2008). Further, Chatterji and Frick (2003, 2005) argue that the decision to return to work after giving birth while still breastfeeding is likely to incur the mother with higher fixed cost of breastfeeding. To the degree that this fixed cost overweighs the benefit of breastfeeding while working, the mother stops her breastfeeding. On the other hand, higher non labor income or higher income obtained before birth may help offset both marginal and fixed cost of breastfeeding associated with maternal work and thus prolong breastfeeding.

\footnotetext{
${ }^{1}$ Exclusive breastfeeding refers to the supply to the infant of only breast milk. Full breastfeeding is the combination of breast milk and water. Any/overall breastfeeding refers to the combination of breast milk with other supplements such as liquid or solid food.
} 
We apply the above model to the rural context of Vietnam to analyze the effects of rainfall shocks on breastfeeding among mothers who live in the rural areas and participate in farming activities. Previous economic literature has documented the link between rainfall and rural household income as well as labor demand. Rainfall shock has been found to have a significant and positive effect on the transitory income of farm household in Southeast Asian agrarian population (Paxson 1992; Yang and Choi 2005). Regarding labor demand, Skoufias (1993, pp. 30-31) found that higher rainfall during the crop cycle causes higher demand for labor both in the planting and harvesting stages in rural India. It is possible that this increased labor demand reduces breastfeeding. Other factors specific to the rural context may intensify the effect of rainfall shocks on breastfeeding. In particular, farming working conditions hardly provide mothers with a friendly breastfeeding environment regarding the places and equipments for lactation. These difficulties come together to increase the cost of breastfeeding and may cause the mother to reduce or stop breastfeeding, as a response to a rainfall shock, earlier than she would under alternative short term weather conditions.

In our empirical analyses we observe rainfall measured in the child's birth place for the years preceding the child's birth and the year of birth. We link the measures of rainfall shock during these years to the length of breastfeeding the child receives. The estimates of these effects of rainfall shock will provide us with the empirical evidence in view of the validity of the above theoretical arguments. In particular, provided that higher rainfall increases labor demand and the opportunity cost of time, the model implies that a positive rainfall shock in the child's birth year, in which competition 
exists between breastfeeding and maternal work, has a negative effect on the duration of breastfeeding.

\section{$3 \quad$ Data and methods}

We use the Vietnam Demographic Health Survey (VNDHS) waves 1997 and 2002. The VNDHS is a stratified and clustered survey, conducted at national level including seven geographic and social economic regions of Vietnam, with the aim to provide information on fertility, family planning, infant and child mortality, and indicators of maternal and child health (NCPFP 1999, 2003).

From the VNDHS we select a sample of children aged between twelve and thirty six months. For this sub-sample we observe both the independent variable, rainfall shocks, and the dependent variable, breastfeeding. We require that children should pass the first twelve months of life so as to receive full information about the rainfall shock in their birth year. The VNDHS also includes information about the socioeconomic characteristics of the mothers; of particular interest is whether the occupation of the mother is in the farming or other sectors. As we expect the rainfall shocks to have differential effects by the mother's farming status, we stratify our analysis according to this variable.

\section{Breastfeeding}

The VNDHS survey has information on the duration of any breastfeeding but not of exclusive or full breastfeeding. We observe directly the (truncated) length of breastfeeding for those children who are still breastfed at the time of the interview. 
For those children for whom breastfeeding has stopped by the time of the interview, their mothers were asked to report the number of rounded months they breastfeed their children. Since we include in the analysis only children aged 36 months or less at the time of survey, we expect that the mother's recall error is small. Some children in the sample have never been breastfed. In our main analysis, we exclude these children because for them the decision about breastfeeding has been done before any of the key independent variable first year rainfall shock has been observed. As shown in our robustness checks later on, this exclusion does not affect our major finding.

We construct two different measures of breastfeeding. The first variable is breastfeeding duration, defined as total number of months during which the child is breastfed. This variable suffers the right censoring problem because some children are still breastfed at the time of the interview. Therefore we also construct indicators for whether breastfeeding has lasted more than 12,18 , or 24 months. Using these binary indicators as the dependent variables avoids the problem of the duration of breastfeeding being truncated at the time of the interview. On the other hand, these cut-offs imply that the child has to be at least 12,18 or 24 months at the time of the interview. Therefore, when estimating the rainfall shock-breastfeeding association for these three binary variables, the size of the estimation samples varies as the number of children aged at least 18 months at the time of the interview (or 24 months) is smaller than the number of children aged at least 12 months.

\section{Rainfall shocks}

Rainfall data, optimally, should be based on the actual data from local weather observatory stations. Such data, however, is typically not available in developing 
country contexts. In the absence of these primary rainfall data, we use the gridded estimates of rainfall provided by the University of Delaware's Center for Climatic Research $^{2}$. This dataset contains global historical estimates of rainfall for a grid of 0.5 by 0.5 degree of geographic coordinates, where the grid nodes are centered on 0.25 degree. We use the coordinates of the VNDHS province of birth to link the child's birth place to the rainfall data. We identify four grid points around the province's coordinate. Province specific rainfall is the average rainfall over these four grids. We use a grid average rather than a single grid rainfall to improve over the potential measurement error in rainfall that arises whenever it is not possible to have rainfall data sufficiently close to the birth locality. We link rainfall data to children by using the information on birth date in the VNDHS.

Rainfall for the birth year is calculated as sum of monthly rainfall for twelve months following the child's month of birth. It is calculated similarly for other years with reference to the child's month of birth. For instance, rainfall for the year in utero is the sum of monthly rainfall for a period of twelve months before the month of birth. The measure of rainfall shock is defined as the deviation of actual rainfall from the provincial average rainfall and calculated as the difference in logarithm of the two respective rainfalls. We calculate the provincial average rainfall based on 55-year annual rainfall series from 1950 to 2004 . The average rainfall has a mean of $1728 \mathrm{~mm}$ and standard deviation of $232 \mathrm{~mm}$. Rainfall shock takes both positive and negative

\footnotetext{
${ }^{2}$ The dataset is provided by Center for Climatic Research, Department of Geography, University of Delaware. Terrestrial Precipitation: 1900-2008 Gridded Monthly Time Series - Version 2.01, interpolated and documented by Kenji Matsuura and Cort J. Willmott (with support from IGES and NASA). For further information about this dataset, please refer to Legates and Willmott (1990).
} 
values and represents the percentage change over the mean. Very large values of rainfall shock indicate extreme weather conditions such as drought or flood, which may influence breastfeeding in a different manner rather than the mechanism under study. Therefore we exclude extreme rainfall shocks, and restrict the range of observed rainfall shocks to be within 35 per cent above or below the mean.

Other studies have used slightly different definitions of the rainfall shocks. Maccini and Yang (2009, pp. 1012) use an interval of two consecutive seasons (12 months) starting with the individual's birth season and this interval may include some months before the month of birth. Godoy et al. (2008) has chosen the 12-month interval that is identical to the calendar year of birth and so this interval may include even more months before the month of birth if the child is born during the second half of the calendar year. Our chosen interval, which is twelve months since the month of birth, is intended to delineate more clearly the timing of rainfall with respect to time after birth and time in utero.

\section{Statistical models}

We estimate a reduced form model in which the dependent variable breastfeeding is regressed on rainfall shocks that an infant experiences during his or her year of birth or year in gestation. These measures of rainfall shock are exogenous in that they are independent of factors such as mother's behaviors or family backgrounds, which might affect breastfeeding. We estimate probability models in which binary dependent variables indicate whether the duration of overall breastfeeding exceeds certain thresholds such as twelve months, eighteen months or twenty four months. While it would also be interesting to consider breastfeeding duration as an outcome, the 
estimation procedure would be more involved due to the right censoring of outcome variable. By focusing on the probability of breastfeeding lasting more than 12,18 , or 24 months, we can overcome the censoring problem and take advantage of all available information.

\section{$4 \quad$ Results}

TABLE 1 ABOUT HERE

Table 1 shows the summary statistics for main variables from subsamples of children with different age groups. The sample sizes drop as we restrict the age of children according to the increase in the threshold for breastfeeding duration. The average durations of breastfeeding vary between 15 and 15.6 months in three subsamples (aged $12+, 18+$ or $24+$ months at the time of the interview) while the percentage of currently being breastfed decreases with age. The proportions of never breastfed children are quite low, being 2 per cent in all subsamples. The distribution of rural or farming households is similar across subsamples. The means of rainfall shock during the birth year are close to zero, suggesting that the negative and positive rainfall shocks in the samples are quite balanced. In Vietnam, annual fluctuation in precipitation follows a tropical monsoon climate system and can be characterized by two seasons of wet and dry. The wet or rainy season, defined as having monthly average rainfall exceeding 100mm (ISPONRE 2009, pp. 35), normally begins in May and ends at the end of September or early October. This timing coincides with the beginning of the summer crop, the second one in a year and follows right after the first one which begins around the end of previous year. Therefore, labor intensity 
usually peaks at this time as farmers are busy with both harvesting and seeding. Rainfall then tends to intensify towards the end of the wet season during months of August to October. During these months, higher frequency of rainy days could create another hectic period as farmers make effort to harvest and to keep farm products in an adequately dry condition.

We start analyzing the association between rainfall shocks and breastfeeding using descriptive parametric and nonparametric regression models and observations in which the breastfeeding had been completed by the time of survey. This cut-off allows using the duration of breastfeeding as the dependent variable, but excludes from the analysis the children who were still breastfed at the time of survey. Table 2 shows the Ordinary Least Square estimates of the coefficients for the effect of rainfall shock in year of birth and year in gestation on duration (in months) of complete breastfeeding. Column 1 shows that the coefficients of rainfall shock in the year of birth are negative and statistically significant when estimated from the whole sample. The estimation with separate samples (farming and non-farming mothers ${ }^{3}$ ) shows that this coefficient continues to be negative but statistically significant only in the farming sample (columns 2 and 3). These estimates indicate that a positive rainfall shock is associated with reduced duration of breastfeeding. For example, a positive shock with a magnitude of 25 per cent above the mean would on average decrease the breastfeeding duration of farming children by 1.4 months. The coefficients of rainfall shock in year of gestation across samples are not significant.

\footnotetext{
${ }^{3}$ In our analysis, non-farming indicates mothers who live either in city or in rural areas but report a non-farming occupation.
} 


\section{TABLE 2 ABOUT HERE}

\section{FIGURE 1 ABOUT HERE}

Figure 1 illustrates the association between breastfeeding duration and rainfall shock by showing the mean breastfeeding by birth year rainfall shock, estimated using locally weighted regression. The solid line is fitted with a sample of children of farming mothers while the dashed line uses a sample of children from non-farming mothers. Again, we observe a negative relationship between rainfall shock in birth year and breastfeeding duration with the farming sample. Over the range in rainfall shock between 25 per cent below and 25 per cent above the mean (representing a 50 per cent increase in rainfall), average breastfeeding duration decreases by about 3 months. Further, the result for the non-farming sample shows no evidence of any relationship.

The results in Table 2 and Figure 1 are based on a sample in which the breastfeeding had been completed for everyone. While this approach is useful as it allows using breastfeeding duration as the dependent variable, the approach also presents two potential problems. First, the sample size is reduced because those who were still being breastfed at the time of interview are excluded, and second, the exclusion may be non-random (in particular those who are breastfed long are at higher risk of being excluded). Next we show that the general relationship between rainfall shock in the year of birth and breastfeeding holds also when the full sample is used and censoring is accounted for. We do this by re-defining the dependent variable to be an indicator for whether breastfeeding lasted beyond 12,18 or 24 months, and by using probit regression models for the binary response variable. 
TABLE 3 ABOUT HERE

Table 3 presents the estimates for the effects of rainfall shock for the three outcomes of breastfeeding duration (12, 18, and 24 months). These are binary outcomes indicating that breastfeeding duration exceeds twelve, eighteen and twenty four months. The estimates are obtained using probit regression method. We account for the possibility that our estimation of rainfall effect may be influenced by birth cohort effects. While in principle the rainfall shocks should be uncorrelated with birth cohort effects, in practice, with a small number of birth cohorts, it is possible that within the data rainfall shocks and changes in breastfeeding practices over birth cohorts correlate. If this is the case, not controlling for the birth cohort results in biased estimates.

When considering all children, the coefficients of rainfall shock in the year of birth are negative for the three outcomes but only statistically significant at 1 per cent level of confidence for the first outcome, breastfeeding over 12 months (columns 1, 2, and 3). As shown earlier, to test the hypothesis that rainfall in the birth year has the effect on breastfeeding through a mechanism in which variation in rainfall affect the mother's agricultural labor demand, in the remainder of Table 3 we stratify the estimation by the mother's status of farming. The estimates obtained with farming sample (columns 4, 5, and 6) show that the coefficients of rainfall shock in the year of birth are consistently negative for each of the outcomes. The coefficients are also significant for the first two outcomes $(12+$ or $18+$ months of breastfeeding); for 24+ months of breastfeeding the magnitude of the coefficients is similar to what it is for 
the other two dependent variables but not significant, potentially because of decreased sample size. These coefficients indicate that a positive rainfall shock in birth year reduces the likelihood that a child is breastfed for more than twelve months or eighteen months.

In the last three columns of Table 3, we show the estimates obtained with non-farming sample. We find no consistent evidence that rainfall shock would influence breastfeeding within this subpopulation. The magnitude of the point estimate for the outcome of breastfeeding over 12 months drops sharply and it is not statistically significant (column 7). On the other hand, the respective coefficient for the outcome of breastfeeding over 18 months and 24 months are positive and insignificant. This evidence thus supports the argument that the rainfall effect on breastfeeding is most likely attributed to the link between rainfall and agricultural livelihood.

Regarding the effect of rainfall shock in the year of gestation, we find that the coefficients for this year are negative and none of them is significant either in the general sample or in the farming sample. We also see a mixed pattern of this coefficient in the estimation with the non-farming group.

\section{TABLE 4 ABOUT HERE}

The main finding emerging from Table 3 is that birth year rainfall predicts decreased breastfeeding among children of farming mothers. Since the coefficients in the probit models do not represent the marginal effect, we calculate the marginal effects and predictive mean of prevalence in the response variables in Table 4. Marginal effects 
are estimated for $12+$ and $18+$ months of breastfeeding and for the farming group (corresponding to the results shown in columns 4 and 5 of Table 3). These estimates show that an increase in rainfall by 100 per cent over the mean is predicted to decrease the proportion breastfeeding over 12 months and 18 months by 37 and 40 percentage points, respectively as shown in the panel A of Table 4. It would be more useful to see how the model predicts changes in breastfeeding in response to more realistic changes in rainfall shock. In the panel B of Table 4, we show changes in predictive mean of the proportion breastfeeding when rainfall deviates by 25 per cent from below and above provincial long run average (Column 1). The effect on the proportion breastfeeding is nonlinear. Column 3 of Table 4 shows that the predicted proportion of children breastfed more than 12 months increases from $80.8 \%$ to $88.6 \%$, or 7.8 percentage points, if rainfall decreases $25 \%$ above its mean, and decreases to $70.3 \%$ (10.5 percentage point drop) if rainfall increases by $25 \%$ above its mean. The changes in the proportion breastfeeding more than 18 months are similar. A $25 \%$ decrease in rainfall increases the proportion breastfeeding more than 18 months from $33.9 \%$ to $44.2 \%$ (10.3 percentage points). A $25 \%$ increase in rainfall decreases the proportion from $33.9 \%$ to $24.7 \%$ (9.2 percentage points)

\section{Robustness checks}

\section{TABLE 5 ABOUT HERE}

We subjected our key finding - that birth year rainfall shocks decrease breastfeeding among children of farming mothers - to an array of robustness checks. First, we address the potential concern that the effect of rainfall in one year could depend on the 
effect of rainfall in adjacent years. If this is the case then the effect of birth year rainfall could be confounded by the presence of rainfall shocks of adjacent years. We study this by estimating the results shown in Table 3 (dependent variables $12+$ or $18+$ months of breastfeeding) with additional controls for rainfall shock two years before birth, and also with no controls for the rainfall shocks before the birth. The estimates in Table 5 show that the key results are consistent across these models.

A second concern is related to the fact that certain number of infants is never breastfed. The analysis so far excluded these infants in all estimation models for the purpose of clarity. To the degree that the decision not to initiate breastfeeding is influenced by rainfall shock, most plausibly in the year of gestation, exclusion of these infants from the model could possibly result in the estimates being biased due to selection. We check for this possibility by adding to the estimation sample the never breastfed infants and re-estimate all models as before. The results are shown in Table 6, and show that the key results remain similar to what we have obtained earlier in Table 3.

\section{TABLE 6 ABOUT HERE}

\section{$5 \quad$ Discussion}

In developing countries, rainfall shocks around the time of birth have been shown to causally influence later health. Prior research has speculated that the mechanism could be related to income shocks, disease exposure, or increasing opportunity cost of parental time. However, none of these mechanisms has been directly tested in a 
developing country context. We analyzed the Vietnam Demographic Health Surveys data to study how rainfall shocks during the years around birth influence a key dimension of parenting behavior, breastfeeding, which is also a key determinant of child health. We find that above average rainfall in the birth year reduces breastfeeding. The effect is particularly strong among children whose mother's livelihood relies on farming, where rainfall is expected to increase the opportunity cost of time through labor demand and practically inexistent among children of nonfarming mothers. These results are the first to shed light on the mechanism linking rainfall shocks to child health in developing countries. In particular, our results provide strong support for the opportunity cost of time theory, which postulates that increasing rainfall increases economic activity and labor demand, thus increasing the opportunity cost of breastfeeding.

Several alternative mechanisms could, in principle, also be at work linking rainfall shocks to decreased breastfeeding. First, it is possible that change in disease prevalence affects the health conditions of both the mother and the child, and this consequently affects breastfeeding. However, disease prevalence most likely surges under extreme weather shocks (WHO 2003, pp. 81). In our analysis, we consider the effect of rainfall in the birth year from a normal range of rainfall shock, excluding outliers, and thus these shocks are less likely to be associated with risk factors of disease exposure. Second, a positive rainfall shock in the birth year could increase income and thus relax the household budget constraint. However, increasing income simultaneously alters the allocation of parental time use. Theoretically, these are known as the income and substitution effects and they jointly determine the decision regarding the amount of child care. The income effect would afford the mother more 
time for her own leisure as well as breastfeeding, while the substitution effect would induce mother to cut back her time input for breastfeeding. Our empirical results support the evidence that the substitution effect might dominate the income effect and they reflect role of opportunity cost of mother's time. This result holds even when the analysis controls for the potential income effect from rainfall shock in the year of gestation. Our results also agree with other findings documented in the existing literature. For instance, Miller and Urdinola (2010, pp. 133-34) find that a fall in the price of coffee in Colombia decrease mother's labor supply and also child morbidity. Miller and Urdinola proxy the monetary return to mother's work with this price change. They show that total effect of price change on mother's work and child health outcome is driven by the substitution effect.

The outcome variable in our study is the duration of any breastfeeding. The theoretical argument that increasing opportunity cost of time decreases breastfeeding is often described in terms of exclusive or full breastfeeding since these types of breastfeeding are rather time consuming and implemented most often during the birth year. However, the argument can easily be extended to the case of overall breastfeeding because the duration of exclusive breastfeeding correlates positively and strongly with that of overall breastfeeding (Chezem et al. 2003). Therefore, our finding that a positive rainfall shock in the birth year causes the mothers to reduce the duration and prevalence of overall breastfeeding is consistent with the theoretical model as discussed earlier. The difference in the effects of rainfall shock during the birth year, when stratified by the farming status of mothers, further supports this theoretical argument. These differences highlight the important role of mother's work intensity in the agricultural sector. Among all crops produced in Vietnam, rice 
cultivation is a seasonally labor intensive work and this crop production employs a larger share of female than male labor. For instance, Kabeer and Tran (2002, pp.124) conducted survey in rural villages in the two deltas of Vietnam and found that over 80 per cent of selected households in Red River Delta and about 67 per cent of selected households in the Mekong Delta report that rice farming activities in their own household are managed by female ranging from land preparation to harvesting. In these rice growing regions, a year with higher rainfall than average could be more favorable to the implementation of rice crops and thus renders postpartum mothers with a more hectic working schedule. Under the time pressure, these mothers are likely to stop their exclusive breastfeeding earlier, to introduce their babies to supplements of liquid and solid foods earlier and consequently shorten the duration of breastfeeding.

In summary, rainfall shocks around the time of birth have been shown to causally influence later health but the mechanism is not known. Our analysis shows that in a developing country rainfall shocks in the year of birth reduce breastfeeding. The effect is particularly strong in farming regions. These results are the first to shed light on the mechanism linking rainfall shocks to child health and provide support for the opportunity cost of parental time mechanism. The mechanism postulates that increasing rainfall increases economic activity and labor demand, thus increasing the opportunity cost of breastfeeding. Policy interventions aiming to improve child health through increased breastfeeding should focus on mitigating the negative impact of increased labor demand on breastfeeding. 


\section{References}

Almond, D. 2006. Is the 1918 influenza pandemic over? Long term effects of in utero influenza exposure in the post 1940 U.S. population, The Journal of Political Economy 114(4): 672-712.

Artero, Enrique, Francisco B. Ortega, Vanesa Espana-Romero, Idoia Labayen, Inge Huybrechts, Angeliki Papadaki, Gerardo Rodriguez, Beatrice Mauro, Kurt Widhalm, Mathilde Kersting, Yannis Manios, Denes Molnar, Luis A. Moreno, Michael Sjostrom, Frederic Gottrand, Manuel J. Castillo, and Stefaan De Henauw on behalf of the HELENA study group. 2010. Longer breastfeeding is associated with increased lower body explosive strength during adolescence, The Journal of Nutrition. doi:10.3945/jn.110.123596.

Baker, Michael and Kevin Milligan. 2008. Maternal employment, breastfeeding, and health: Evidence from maternity leave mandates, Journal of Health Economics 27: 871-887.

Bengtsson, Tommy and Martin Lindström. 2000. Childhood misery and disease in later life: The effects on mortality in old age of hazards experienced in early life, southern Sweden, 1760-1894, Population Studies 54: 263-277.

Bhalotra, S. 2010. Fatal fluctuations? Cyclicality in infant mortality in India, Journal of Development Economics 93: 7-19.

Barker, D.J.P. 2001. Fetal and infant origins of adult disease, Monatsschr Kinderheilkd 149: S2-S6.

Bozzoli, Carlos, Angus Deaton, and Climent Quintana-Domeque. 2009. Adult Height and Childhood Diseases, Demography 46(4): 647-669.

Chatterji, Pinka and Kevin Frick. 2003. Does returning to work after childbirth affect breastfeeding practices? National Bureau of Economic Research, Working Paper 9630.

Chatterji, Pinka and Kevin Frick. 2005. Does returning to work after childbirth affect breastfeeding practices? Review of Economics of the Household 3(3): 315-335.

Chezem, JoCarol, Carol Friesen, and Joan Boettcher. 2003. Breastfeeding knowledge, breastfeeding confidence, and infant feeding plans: Effects on actual feeding practices, Journal of Obstetric, Gynecologic and Neonatal Nursing 32: 40-47.

Dehejia, Rajeev and Adriana Lleras-Muney. 2004. Booms, busts, and babies' health, The Quarterly Journal of Economics 119(3): 1091-1130.

Dennis, C-L. 2002. Breastfeeding initiation and duration: A 1990-2000 literature review, Journal of Obstetric Gynecologic and Neonatal Nursing 31(1): 12-32. 
Fall, Caroline, Judith B Borja, Clive Osmond, Linda Richter, Santosh K Bhargava, Reynaldo Martorell, Aryeh D Stein, Fernando C Barros, Cesar G Victora and the COHORTS group. 2011. Infant-feeding patterns and cardiovascular risk factors in young adulthood: data from five cohorts in low- and middle-income countries, International Journal of Epidemiology 40(1): 47-62.

Finch, Caleb and Eileen M. Crimmins. 2004. Inflammatory Exposure and Historical Changes in Human Life-Spans, Science 305(1736): 1736-1739.

Godoy, Ricardo, Susan Tanner, Victoria Reyes-Garci, William R. Leonard, Thomas W. Mcdade, Melanie Vento, James Broesch, Ian C. Fitzpatrick, Peter Giovannini, Tomas Huanca, and Naveen Jha Bolivian Taps study team. 2008. The effect of rainfall during gestation and early childhood on adult height in a foraging and horticultural society of the Bolivian Amazon, American Journal of Human Biology 20: 23-34.

Hoddinott, John and Bill Kinsey. 2001. Child growth in the time of drought, Oxford Bulletin of Economics and Statistics 63(4): 409-436.

Institute of Strategy and Policy on Natural Resources and Environment (ISPONRE). 2009. Chapter 2: Climate Change and Scenarios in Viet Nam, in Viet Nam Assessment Report on Climate Change (VARCC).

Kabeer, Naila and Tran Thi Van Anh. 2002. "Leaving the rice field but not the countryside" Gender, livelihood diversification and pro-poor growth in rural Vietnam, in Shifting Burdens: Gender and Agrarian Change under Neoliberalism.

Kramer, Michael, Frances Aboud, Elena Mironova, Irina Vanilovich, Robert W. Platt, Lidia Matush, Sergei Igumnov, Eric Fombonne, Natalia Bogdanovich, Thierry Ducruet, Jean-Paul Collet, Beverley Chalmers, Ellen Hodnett, Sergei Davidovsky, Oleg Skugarevsky, Oleg Trofimovich, Ludmila Kozlova, Stanley Shapiro, for the Promotion of Breastfeeding Intervention Trial (PROBIT) Study Group. 2008. Breastfeeding and child cognitive development - New evidence from a large randomized trial, Archives of General Psychiatry 65(5): 578-584.

Kramer, Michael. 2010. Breastfeeding, complementary (solid) foods, and long-term risk of obesity, The American Journal of Clinical Nutrition 91: 500-501.

Maccini, Sharon and Dean Yang. 2009. Under the weather: health, schooling, and economic consequences of early-life rainfall, The American Economic Review 99(3): 1006-1026.

Miller, Grant and B. Piedad Urdinola. 2010. Cyclicality, mortality, and the value of time: the case of coffee price fluctuations and child survival in Colombia, Journal of Political Economy 118(1): 113-155.

National Committee for Population and Family Planning - The Population and Family Health Project (1999). Vietnam - Demographic and Health Survey 1997. 
National Committee for Population, Family and Children - Population and Family Health Project, Hanoi - September 2003: Vietnam Demographic and Health Survey 2002.

Legates, David and Cort J. Willmott. 1990. Mean seasonal and spatial variability in gauge-corrected, global precipitation, International Journal of Climatology 10(2): 111-127.

Paxson, C.H. 1992. Using weather variability to estimate the response of savings to transitory income in Thailand, The American Economic Review 82(1): 15-33.

Roe, Brian, Leslie A. Whittington, Sara Beck Fein and Mario F. Teisl. 1999. Is there competition between breastfeeding and maternal employment? Demography 36(2): $157-171$.

Skoufias, E. 1993. Seasonal labor utilization in agriculture: theory and evidence from agrarian households in India, American Journal of Agricultural Economics 75(1): 20 32.

Skoufias, Emmanuel and Katja Vinha. 2011. Climate variability and child height in rural Mexico, Economics and Human Biology, doi:10.1016/j.ehb.2011.06.001.

Yang, Dean and HwaJung Choi. 2007. Are remittances insurance? Evidence from rainfall shocks in the Philippines, The World Bank Economic Review 21(2): 219-248.

World Health Organization. 2003. Global Strategy for Infant and Young Child Feeding.

World Health Organization. 2003. Chapter 5: Impacts on health of climate extremes in Climate Change and Human Health - RISKS AND RESPONSES. 
TABLES AND FIGURES

Table 1 - Summary Statistics

\begin{tabular}{|c|c|c|c|c|c|}
\hline Variable & Mean & $\begin{array}{l}\text { Std. } \\
\text { Dev. }\end{array}$ & Min & Max & $\mathrm{N}$ \\
\hline \multicolumn{6}{|l|}{$\begin{array}{l}\text { Age above } 12 \text { months at the time of the } \\
\text { interview }\end{array}$} \\
\hline Age in months & 23.4 & 6.5 & 13 & 35 & 1528 \\
\hline Birth year & 1997 & 3 & 1994 & 2001 & 1528 \\
\hline $\begin{array}{l}\text { Complete breastfeeding duration } \\
\text { (months) }\end{array}$ & 15.01 & 4.56 & 0 & 30 & 1027 \\
\hline Breastfed over 12 months ( $1=$ yes) & 0.77 & 0.42 & 0 & 1 & 1528 \\
\hline Currently being breastfed (1=yes) & 0.31 & 0.46 & 0 & 1 & 1495 \\
\hline Never breastfed (1=yes) & 0.02 & 0.15 & 0 & 1 & 1528 \\
\hline Rainfall shock in year of birth & 0.02 & 0.15 & -0.35 & 0.35 & 1528 \\
\hline Rainfall shock in year of gestation & 0.02 & 0.18 & -0.35 & 0.35 & 1528 \\
\hline Rural residence (1=yes) & 0.82 & 0.39 & 0 & 1 & 1528 \\
\hline Farming occupation (1=yes) & 0.63 & 0.48 & 0 & 1 & 1528 \\
\hline \multicolumn{6}{|l|}{$\begin{array}{l}\text { Age above } 18 \text { months at the time of the } \\
\text { interview }\end{array}$} \\
\hline Age in months & 26.5 & 4.8 & 19 & 35 & 1096 \\
\hline Birth year & 1997 & 3 & 1994 & 2001 & 1096 \\
\hline $\begin{array}{l}\text { Complete breastfeeding duration } \\
\text { (months) }\end{array}$ & 15.39 & 4.54 & 0 & 30 & 897 \\
\hline Breastfeeding over 18 months & 0.30 & 0.46 & 0 & 1 & 1096 \\
\hline Currently being breastfed ( $1=y e s)$ & 0.16 & 0.37 & 0 & 1 & 1071 \\
\hline Never breastfed (1=yes) & 0.02 & 0.15 & 0 & 1 & 1096 \\
\hline Rainfall shock in year of birth & 0.00 & 0.15 & -0.33 & 0.35 & 1096 \\
\hline Rainfall shock in year of gestation & 0.03 & 0.19 & -0.35 & 0.35 & 1096 \\
\hline Rural residence (1=yes) & 0.82 & 0.38 & 0 & 1 & 1096 \\
\hline Farming occupation (1=yes) & 0.63 & 0.48 & 0 & 1 & 1096 \\
\hline \multicolumn{6}{|l|}{$\begin{array}{l}\text { Age above } 24 \text { months at the time of the } \\
\text { interview }\end{array}$} \\
\hline Age in months & 29.8 & 3.2 & 25 & 35 & 652 \\
\hline Birth year & 1997 & 3 & 1994 & 2000 & 652 \\
\hline $\begin{array}{l}\text { Complete breastfeeding duration } \\
\text { (months) }\end{array}$ & 15.62 & 5 & 0 & 30 & 578 \\
\hline Breastfeeding over 24 months & 0.11 & 0.32 & 0 & 1 & 652 \\
\hline Currently being breastfed ( $1=$ yes) & 0.09 & 0.29 & 0 & 1 & 636 \\
\hline Never breastfed (1=yes) & 0.02 & 0.15 & 0 & 1 & 652 \\
\hline Rainfall shock in year of birth & -0.04 & 0.16 & -0.33 & 0.35 & 652 \\
\hline Rainfall shock in year of gestation & 0.09 & 0.17 & -0.32 & 0.35 & 652 \\
\hline Rural residence (1=yes) & 0.83 & 0.37 & 0 & 1 & 652 \\
\hline Farming occupation (1=yes) & 0.65 & 0.48 & 0 & 1 & 652 \\
\hline
\end{tabular}

Note: Data sources are Vietnam Demographic and Health Survey (1997 and 2002) and University of Delaware's Center for Climatic Research. Rainfall shock is defined as deviation of rainfall from the long-run provincial average. Birth year rainfall is sum of 12 monthly rainfall amounts following the birth month. 
Table 2 - Rainfall shocks and breastfeeding duration

\begin{tabular}{lccc}
\hline & \multicolumn{3}{c}{ Breastfeeding duration } \\
& Whole sample & Farming & Non-farming \\
& $(1)$ & $(2)$ & $(3)$ \\
\hline \multirow{2}{*}{ Rainfall shock in year of birth } & $-3.868^{* *}$ & $-5.579^{* *}$ & -1.074 \\
& $(1.020)$ & $(1.327)$ & $(1.151)$ \\
Rainfall shock in year of gestation & -0.843 & -0.324 & -1.184 \\
& $(1.000)$ & $(1.305)$ & $(1.311)$ \\
\hline $\mathrm{R}$ square & 0.019 & 0.034 & 0.004 \\
$\mathrm{~N}$ & 1027 & 613 & 414 \\
\hline
\end{tabular}

Note: Data sources are Vietnam Demographic and Health Survey (1997 and 2002) and University of Delaware's Center for Climatic Research. Rainfall shock is defined as deviation of rainfall from the long-run provincial average. Birth year rainfall is sum of 12 monthly rainfall amounts following the birth month. Non-farming indicates mothers who live either in city or in rural areas but report a nonfarming occupation. Regressions are OLS and include constants. Dependent variable is duration (in months) of complete breastfeeding. Therefore a coefficient of, say -3.9 implies that a $100 \%$ increase in rainfall over the provincial average is associated with a 3.9 month reduction in breastfeeding duration. Samples in columns 1, 2 and 3 include only the ever breastfed children aged above 12 months at the time of interview and for whom breastfeeding has stopped. Estimates of standard errors (in parenthesis) are robust and adjusted for the clustering at the regional level. $+\mathrm{p}<0.10$, * $\mathrm{p}<0.05, * * \mathrm{p}<0.01$ 
Table 3 -Rainfall Shocks and Breastfeeding (BR) Prevalence

\begin{tabular}{|c|c|c|c|c|c|c|c|c|c|}
\hline & \multicolumn{2}{|c|}{ Whole sample } & \multicolumn{3}{|c|}{ Farming } & \multicolumn{3}{|c|}{ Non-farming } & \multirow[b]{2}{*}{$\begin{array}{c}\mathrm{BR}>24 \\
\text { months } \\
\text { (9) }\end{array}$} \\
\hline & $\begin{array}{c}\mathrm{BR}>12 \\
\text { months } \\
(1)\end{array}$ & $\begin{array}{c}\mathrm{BR}>18 \\
\text { months } \\
(2)\end{array}$ & $\begin{array}{c}\mathrm{BR}>24 \\
\text { months } \\
(3)\end{array}$ & $\begin{array}{c}\mathrm{BR}>12 \\
\text { months } \\
(4)\end{array}$ & $\begin{array}{c}\mathrm{BR}>18 \\
\text { months } \\
(5)\end{array}$ & $\begin{array}{c}\mathrm{BR}>24 \\
\text { months } \\
(6)\end{array}$ & $\begin{array}{c}\text { BR }>12 \\
\text { months } \\
(7)\end{array}$ & $\begin{array}{c}\mathrm{BR}>18 \\
\text { months } \\
(8)\end{array}$ & \\
\hline Rainshock, year of birth & $\begin{array}{c}-1.068 * * \\
(0.364)\end{array}$ & $\begin{array}{l}-0.612 \\
(0.375)\end{array}$ & $\begin{array}{l}-0.034 \\
(0.461)\end{array}$ & $\begin{array}{c}-1.424 * * \\
(0.483)\end{array}$ & $\begin{array}{c}-1.106 * * \\
(0.424)\end{array}$ & $\begin{array}{l}-0.380 \\
(0.447)\end{array}$ & $\begin{array}{l}-0.724 \\
(0.465)\end{array}$ & $\begin{array}{c}0.663 \\
(0.623)\end{array}$ & $\begin{array}{c}1.613 \\
(1.133)\end{array}$ \\
\hline $\begin{array}{l}\text { Rainshock, the year } \\
\text { preceding birth }\end{array}$ & $\begin{array}{l}-0.490 \\
(0.305)\end{array}$ & $\begin{array}{l}-0.037 \\
(0.210)\end{array}$ & $\begin{array}{l}-0.302 \\
(0.400)\end{array}$ & $\begin{array}{l}-0.010 \\
(0.350)\end{array}$ & $\begin{array}{l}-0.131 \\
(0.326)\end{array}$ & $\begin{array}{l}-0.662 \\
(0.512)\end{array}$ & $\begin{array}{l}-0.995^{*} \\
(0.394)\end{array}$ & $\begin{array}{c}0.171 \\
(0.293)\end{array}$ & $\begin{array}{c}1.204 \\
(0.789)\end{array}$ \\
\hline $\begin{array}{l}\text { R-squared } \\
\mathrm{N}\end{array}$ & $\begin{array}{c}0.029 \\
1483\end{array}$ & $\begin{array}{c}0.022 \\
1062\end{array}$ & $\begin{array}{c}0.018 \\
628\end{array}$ & $\begin{array}{c}0.045 \\
914\end{array}$ & $\begin{array}{c}0.025 \\
661\end{array}$ & $\begin{array}{c}0.027 \\
401\end{array}$ & $\begin{array}{c}0.027 \\
569\end{array}$ & $\begin{array}{c}0.040 \\
401\end{array}$ & $\begin{array}{c}0.052 \\
210\end{array}$ \\
\hline
\end{tabular}

Note: Data sources are Vietnam Demographic and Health Survey (1997 and 2002) and University of Delaware's Center for Climatic Research. Rainfall shock is defined as deviation of rainfall from the provincial average. Birth year rainfall is sum of 12 monthly rainfall amounts following the birth month. Non-farming indicates mothers who live either in city or in rural areas but report a non-farming occupation. All results are based on probit regressions models with birth cohort dummies and constants.

Dependent variables are binary outcomes of whether being breastfed over 12, 18 and 24 months. Sample in each column includes the ever breastfed children age above 12 , 18 and 24 months in accordance with dependent variables. Estimates of standard errors (in parenthesis) are robust and adjusted for the clustering at the regional level. BR and YOB stands for breastfeeding and year of birth, respectively. $+\mathrm{p}<0.10, * \mathrm{p}<0.05, * * \mathrm{p}<0.01$ 
Table 4 - Marginal effect and predictions for the effects of rainfall shock

A. Marginal effect of the coefficients for rainfall shock

\begin{tabular}{lc}
\hline & $\begin{array}{c}\text { Marginal effect } \\
\text { (standard error) of birth year rainfall } \\
\text { shock }\end{array}$ \\
\hline Probability of breastfeeding more than 12 months & -0.374 \\
Probability of breastfeeding more than 18 months & $(0.124)$ \\
& -0.397 \\
\hline
\end{tabular}

B. Predictive effects of a modest birth year rainfall shock

\begin{tabular}{lcccc}
\hline Rainfall shock & $\begin{array}{c}\text { Proportion of } \\
\text { children breastfed } \\
>12 \text { months } \\
(2)\end{array}$ & $\begin{array}{c}\text { Change in } \\
\text { the } \\
\text { proportion } \\
(1)\end{array}$ & $\begin{array}{c}\text { Proportion of } \\
\text { children breastfed } \\
>18 \text { months }\end{array}$ & $\begin{array}{c}\text { Change in } \\
\text { the } \\
\text { proportion } \\
(5)\end{array}$ \\
\hline $\begin{array}{l}\text { 25\% below average } \\
\text { Equal the average }\end{array}$ & 0.886 & 0.078 & 0.442 & 0.103 \\
25\% above average & 0.808 & -0.105 & 0.339 & -0.092 \\
\hline
\end{tabular}

Note: The calculations for marginal effects and predictive means are based on the estimates obtained from columns 4 and 5 of Table 3. Marginal effects indicate that a positive rainfall shock, with magnitude of 100 per cent deviation of rainfall from the long-run average, would decrease the probability that the child is breastfed more than 12 months by 37.4 percentage points. Similarly, this rainfall shock would decrease the probability that the child is breastfed more than 18 months by 39.7 percentage points. Predictive effects of rainfall shocks are in terms of change in predictive mean over a range of rainfall shock. For instance, mean proportion of children breastfed more than 12 months is estimated at 80.8 per cent under normal rain. This mean proportions increases to 88.6 per cent when rainfall shock is 25 per cent below long run provincial average ( 7.8 percentage points) and decreases to 70.3 per cent when rainfall shock is 25 per cent above average (10.5 percentage points). 
Table 5 - Robustness of the results to controls for pre-birth rainfall shocks.

\begin{tabular}{|c|c|c|c|c|c|c|}
\hline & \multicolumn{3}{|c|}{$\mathrm{BR}^{1}>12$ months } & \multicolumn{3}{|c|}{$\mathrm{BR}>18$ months } \\
\hline & (1) & (2) & (3) & (4) & $(5)$ & (6) \\
\hline \multicolumn{7}{|l|}{ A. General sample } \\
\hline Rainshock $\mathrm{YOB}^{2}$ & $\begin{array}{c}-1.091 * * \\
(0.364)\end{array}$ & $\begin{array}{c}-1.068 * * \\
(0.364)\end{array}$ & $\begin{array}{c}-0.831^{*} \\
(0.406)\end{array}$ & $\begin{array}{c}-0.615+ \\
(0.372)\end{array}$ & $\begin{array}{l}-0.612 \\
(0.375)\end{array}$ & $\begin{array}{c}-0.576 \\
(0.423)\end{array}$ \\
\hline Rainshock YOB-1 & & $\begin{array}{l}-0.490 \\
(0.305)\end{array}$ & $\begin{array}{l}-0.448 \\
(0.300)\end{array}$ & & $\begin{array}{l}-0.037 \\
(0.210)\end{array}$ & $\begin{array}{l}-0.034 \\
(0.204)\end{array}$ \\
\hline Rainshock YOB-2 & & & $\begin{array}{l}-0.322 \\
(0.261)\end{array}$ & & & $\begin{array}{l}-0.039 \\
(0.215)\end{array}$ \\
\hline $\mathrm{R}$ - square & 0.026 & 0.029 & 0.032 & 0.022 & 0.022 & 0.022 \\
\hline $\mathrm{N}$ & 1483 & 1483 & 1483 & 1062 & 1062 & 1062 \\
\hline \multicolumn{7}{|l|}{ B. Farming group } \\
\hline Rainshock YOB & $\begin{array}{c}-1.424 * * \\
(0.481)\end{array}$ & $\begin{array}{c}-1.424 * * \\
(0.483)\end{array}$ & $\begin{array}{l}-1.378 * \\
(0.573)\end{array}$ & $\begin{array}{c}-1.103 * * \\
(0.426)\end{array}$ & $\begin{array}{c}-1.106 * * \\
(0.424)\end{array}$ & $\begin{array}{l}-0.994 * \\
(0.481)\end{array}$ \\
\hline Rainshock YOB-1 & & $\begin{array}{c}-0.010 \\
(0.350)\end{array}$ & $\begin{array}{l}-0.006 \\
(0.344)\end{array}$ & & $\begin{array}{l}-0.131 \\
(0.326)\end{array}$ & $\begin{array}{l}-0.125 \\
(0.315)\end{array}$ \\
\hline Rainshock YOB-2 & & & $\begin{array}{l}-0.052 \\
(0.325)\end{array}$ & & & $\begin{array}{l}-0.117 \\
(0.252)\end{array}$ \\
\hline $\mathrm{R}$ - square & 0.045 & 0.045 & 0.045 & 0.025 & 0.025 & 0.026 \\
\hline $\mathrm{N}$ & 914 & 914 & 914 & 661 & 661 & 661 \\
\hline \multicolumn{7}{|c|}{ C. Non-farming group } \\
\hline Rainshock YOB & $\begin{array}{c}-0.786+ \\
(0.457)\end{array}$ & $\begin{array}{l}-0.724 \\
(0.465)\end{array}$ & $\begin{array}{c}-0.417 \\
(0.511)\end{array}$ & $\begin{array}{c}0.687 \\
(0.623)\end{array}$ & $\begin{array}{c}0.663 \\
(0.623)\end{array}$ & $\begin{array}{c}0.366 \\
(0.730)\end{array}$ \\
\hline Rainshock YOB-1 & & $\begin{array}{l}-0.995^{*} \\
(0.394)\end{array}$ & $\begin{array}{l}-0.930 * \\
(0.398)\end{array}$ & & $\begin{array}{c}0.171 \\
(0.293)\end{array}$ & $\begin{array}{c}0.130 \\
(0.293)\end{array}$ \\
\hline Rainshock YOB-2 & & & $\begin{array}{l}-0.562+ \\
(0.309)\end{array}$ & & & $\begin{array}{c}0.388 \\
(0.383)\end{array}$ \\
\hline R-square & 0.013 & 0.027 & 0.033 & 0.039 & 0.040 & 0.042 \\
\hline $\mathrm{N}$ & 569 & 569 & 569 & 401 & 401 & 401 \\
\hline
\end{tabular}

Note: Data sources are Vietnam Demographic and Health Survey (1997 and 2002) and University of Delaware's Center for Climatic Research. Rainfall shock is defined as deviation of rainfall from the provincial average. Birth year rainfall is sum of 12 monthly rainfall amounts following the birth month. Non-farming indicates mothers who live either in city or in rural areas but report a non-farming occupation. All regressions use probit estimation method and include birth cohort dummies and constants. Dependent variables are binary outcomes of whether being breastfed over 12 and 18 months. Samples include the ever breastfed children age above 12 and 18 months in accordance with dependent variables. Estimates of standard errors (in parentheses) are robust and adjusted for the clustering at the regional level. $+\mathrm{p}<0.10,{ }^{*} \mathrm{p}<0.05,{ }^{* *} \mathrm{p}<0.01$

${ }^{1}$ Breastfeeding

${ }^{2}$ Year of Birth 
Table 6 - Robustness of the results to inclusion of never breastfed children.

\begin{tabular}{|c|c|c|c|c|c|c|c|c|c|}
\hline & \multicolumn{2}{|c|}{ Whole sample } & \multicolumn{3}{|c|}{ Farming } & \multicolumn{3}{|c|}{ Non-farming } & \multirow[b]{2}{*}{$\begin{array}{c}\mathrm{BR}>24 \\
\text { months } \\
\quad(9)\end{array}$} \\
\hline & $\begin{array}{c}\mathrm{BR}^{1}>12 \\
\text { months } \\
(1)\end{array}$ & $\begin{array}{c}\mathrm{BR}>18 \\
\text { months } \\
(2)\end{array}$ & $\begin{array}{c}\mathrm{BR}>24 \\
\text { months } \\
\text { (3) }\end{array}$ & $\begin{array}{c}\mathrm{BR}>12 \\
\text { months } \\
(4)\end{array}$ & $\begin{array}{c}\mathrm{BR}>18 \\
\text { months } \\
(5)\end{array}$ & $\begin{array}{c}\text { BR }>24 \\
\text { months } \\
\text { (6) }\end{array}$ & $\begin{array}{c}\mathrm{BR}>12 \\
\text { months } \\
(7)\end{array}$ & $\begin{array}{c}\mathrm{BR}>18 \\
\text { months } \\
(8)\end{array}$ & \\
\hline Rainshock YOB ${ }^{2}$ & $\begin{array}{c}-1.016^{* *} \\
(0.331)\end{array}$ & $\begin{array}{c}-0.652+ \\
(0.369)\end{array}$ & $\begin{array}{l}-0.106 \\
(0.445)\end{array}$ & $\begin{array}{c}-1.566^{* *} \\
(0.431)\end{array}$ & $\begin{array}{c}-1.155^{* *} \\
(0.414)\end{array}$ & $\begin{array}{l}-0.486 \\
(0.444)\end{array}$ & $\begin{array}{c}-0.483 \\
(0.438)\end{array}$ & $\begin{array}{c}0.618 \\
(0.627)\end{array}$ & $\begin{array}{c}1.576 \\
(1.144)\end{array}$ \\
\hline Rainshock YOB-1 & $\begin{array}{c}-0.515+ \\
(0.298)\end{array}$ & $\begin{array}{c}-0.054 \\
(0.211)\end{array}$ & $\begin{array}{c}-0.287 \\
(0.395)\end{array}$ & $\begin{array}{c}-0.074 \\
(0.345)\end{array}$ & $\begin{array}{l}-0.149 \\
(0.327)\end{array}$ & $\begin{array}{c}-0.642 \\
(0.504)\end{array}$ & $\begin{array}{c}-0.944 * * \\
(0.365)\end{array}$ & $\begin{array}{c}0.150 \\
(0.297)\end{array}$ & $\begin{array}{c}1.196 \\
(0.776)\end{array}$ \\
\hline R-square & 0.029 & 0.023 & 0.017 & 0.049 & 0.026 & 0.027 & 0.022 & 0.040 & 0.051 \\
\hline $\mathrm{N}$ & 1528 & 1096 & 652 & 941 & 683 & 417 & 587 & 413 & 218 \\
\hline
\end{tabular}

Note: Data sources are Vietnam Demographic and Health Survey (1997 and 2002) and University of Delaware's Center for Climatic Research. Rainfall shock is defined as deviation of rainfall from the provincial average. Birth year rainfall is sum of 12 monthly rainfall amounts following the birth month Non-farming indicates mothers who live either in city or in rural areas but report a non-farming occupation. All regressions use probit estimation method and include birth cohort dummies and constants. Dependent variables are binary outcomes of whether being breastfed over 12, 18 and 24 months. Samples include both the ever and the never breastfed children age above 12, 18 and 24 months in accordance with dependent variables. Estimates of standard errors (in parenthesis) are robust and adjusted for the clustering at the regional level. $+\mathrm{p}<0.10, * \mathrm{p}<0.05, * * \mathrm{p}<0.01$

${ }^{1}$ Breastfeeding

${ }^{2}$ Year of Birth 


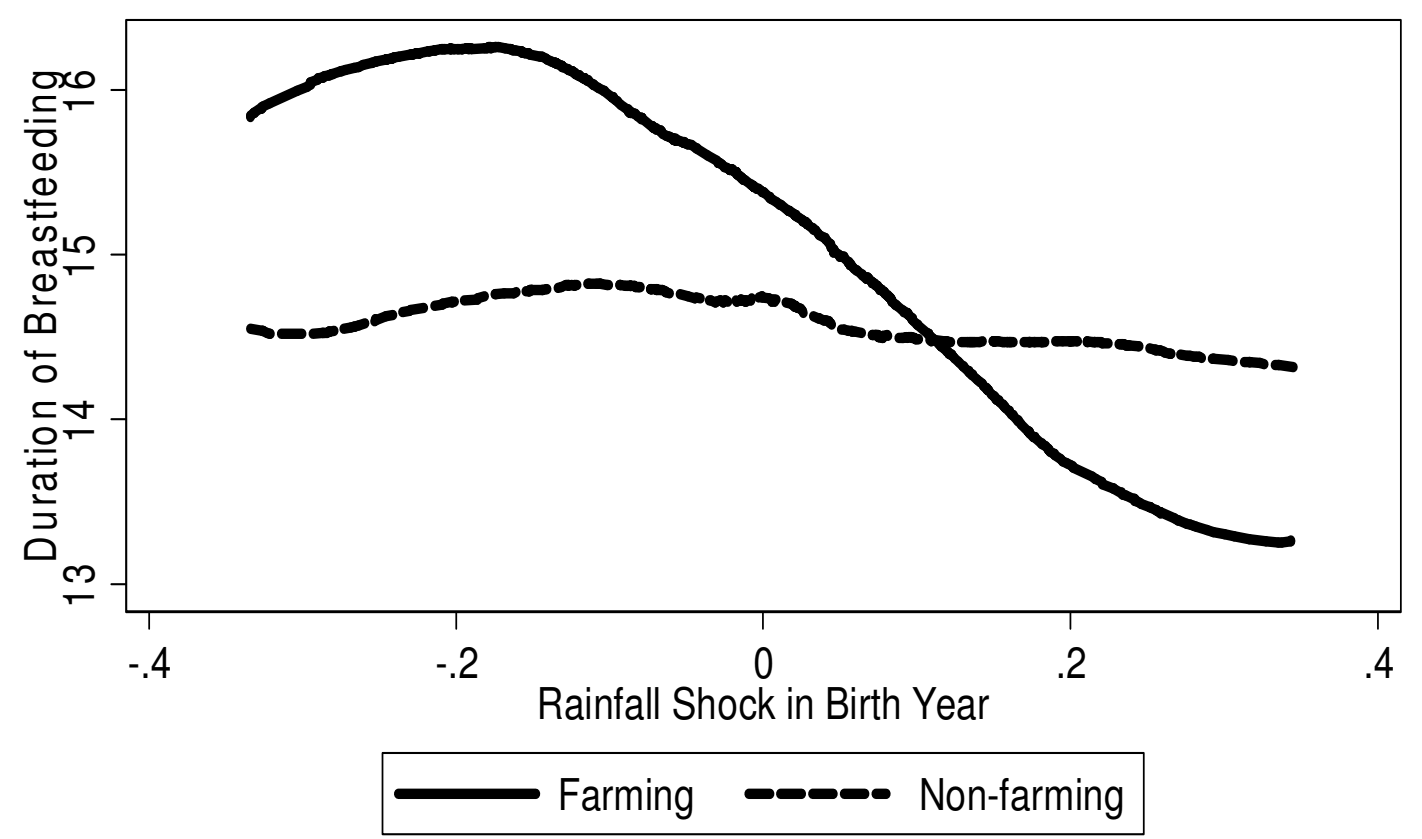

\section{Figure 1: Effect of Rainfall on Breastfeeding Duration}

Note: Graphs use the method of locally weighted regression with bandwidth of 0.8 and sample with complete breastfeeding information. Data sources are Vietnam Demographic and Health Survey(1997 and 2002) and University of Delaware's Center for Climatic Research. Rainfall shock is defined as deviation of rainfall from the long-run provincial average. Duration of breastfeeding is total number of months the child is breastfed. Birth year rainfall is sum of 12 monthly rainfall amounts following the birth month. Non-farming indicates mothers who live either in city or in rural areas but report a non-farming occupation. 